\title{
The Research on Training Mode of Professional Postgraduate students in Civil Engineering Colleges and Universities
}

\author{
Yan Li ${ }^{\mathrm{a}}$, Xin Qi \\ College of Civil Engineering, Jilin Jianzhu University, Changchun, 130021 \\ a1092938725@qq.com
}

\begin{abstract}
Keywords: Civil engineering colleges; Postgraduate; Engineering Research Center; Training mode
\end{abstract}

\begin{abstract}
The post-graduate training mode has been one of the most important tasks of Green Building Engineering Research Center for Cold Area, Jilin Jianzhu University. Great efforts have been paid from all aspects to improve the quality of postgraduate education in recent years. In this paper, a brief introduction to the post-graduate training mode of Engineering Research Center of JLJZU is given. Problems in practice and possible solutions are also discussed.
\end{abstract}

\section{Introduction}

Green Building Technology Engineering Research Center for Cold Area which is established in Jilin Jianzhu University, is the key research base of Jilin province building technology and is the platform where scientific achievements of engineering and industrialization as well as gathering. The recruits and cultivation of postgraduate are made through engineering consultancy and scientific research project application in the Engineering research center, in where currently scientific research projects undertaken are mainly completed by the postgraduates under the guidance of their supervisors. Therefore, the quality of postgraduate training is not only relevant to the strength of scientific research capability in research center, but also a symbol of embodying the quality of a university's training talent.

Since the 1990s, all kinds of scientific research institutions in Chinese universities, have all developed rapidly. In the early 1990s, the total number of scientific research institutions in colleges and universities reached more than 1,600. By 2004, the total number of scientific research institutions in colleges and universities reached more than 5,000, among which there were more than 2,000 scientific research institutions in key universities and nearly 3,000 scientific research institutions in ordinary universities ${ }^{[1]}$. These institutions play a significant role in the application and undertaking of scientific research projects as well as the cultivation of doctoral and postgraduate talents. Therefore, in recent years, colleges and universities have paid more and more attention to how to create an innovative environment for postgraduate education in the engineering research center.

At present, China's annual enrollment number of master's students has reached more than 400,000 people. From the perspective of the employment trend of postgraduates, a large number of them are moving towards the practical field of society. Main problems of postgraduate education in our country are as followings: the adaptability of talent training is not strong, there is a disconnect phenomenon between postgraduate education and social economic development needs, of all which seriously affected the sustainable development of graduate education. Therefore, We should optimize the enrollment structure for master's degree programs, adjusting the training objectives for master's degree programs, strengthening the training of application-oriented high-level talents, and boosting the effective connection between talent training and social needs.

In recent years, with the continual increasing in terms of introducing talents in colleges and universities as well as scientific research funds investment. Among many colleges and universities, the research center constructed specifically following some discipline direction gradually starts to obtain the first-class research team and more abundant research funding, of which in a certain degree can guarantee that the university implement more advanced graduate education theory ${ }^{[2]}$. 
According to its own conditions, Green Building Technology Engineering for Cold Area research center of Jilin Jianzhu university has made a serious attempt to the postgraduate training mode of the center. We are actively learning the postgraduate cultivating mode from the various domestic brothers colleges. Aiming at the specific condition of center, via practice gradually established a special research centre and the environment that matches the postgraduate training and management system ${ }^{[3]}$. The following are the main aspects of our research center's postgraduate education model and postgraduate education environment innovation.

\section{Establish a scientific research echelon with high-level supervisors as the core}

Without high-level postgraduate supervisors, it is difficult to produce high-quality postgraduate students. Green Building Technology Engineering Research Center for Cold Area, which was established in 2007, is approved by the Jilin provincial education department as Jilin province engineering research center of higher education. According to the overall development planning drafted by Jilin Jianzhu university and aiming at the characteristics of the cold climate in our province, the research center determined the direction toward scientific research mainly centered on civil engineering construction quality and material related project in our province. Through cooperation and exercise of the provincial key projects, forming the research team capable of being innovative and with strong ability of scientific research.To provide scientific and accurate experiment data, the center actively participated in the provincial quality inspection of civil construction project as well as ranking assessment and analysis activities of engineering quality accident investigation, dealing with the problems of controversial experimental data of various test and detection institutions, and provided a more advanced research base for teachers' scientific research. At the same time, the center accepted the commission, offering technical advice, business guidance and training services outward. The research center began to recruit postgraduate students in 2009. So far, more than 20 postgraduate students have graduated, and some of them have been admitted to Harbin Institute of Technology and Beijing institute of technology for doctoral studies. With the director of the research center as the core and members of the academic committee as the representatives, the center encourages young teachers and researchers to participate in the training of postgraduates. The famous scholars invited by the research center in various ways also directly participate in the training of postgraduates. In such a competitive strength of the supervisor team, fundamentally ensure the quality of postgraduate training center.

\section{Establish a practice base for the joint cultivation of postgraduate students by the department, civil engineering external units, and engineering research center}

The engineering research center of civil engineering colleges and universities is the carrier of practical engineering research, and the major practice is both an important part of full-time postgraduate students training and a fundamental guarantee for the quality of postgraduate education. Through the cooperation between the school department, especially the civil engineering external units and the engineering research center, the construction research of the joint training base for postgraduate students is carried out, focusing on the combination of postgraduate students' theory and engineering practice. The topic selection of postgraduate students takes solving practical engineering problems as the main goal. In order to truly achieve the aim of training comprehensive and applied postgraduate students, the engineering research center attaches great importance to the whole process of the cultivation of postgraduate students who work in the center, trying hard to practice the program of cultivating jointly with other external units, specifically analyzing the center's training mechanism and its implementation strategy of inter-disciplinary double tutorial system as well as the dissertation topic selection and the existed cultivation model in order to realize the organic integration. 


\section{Actively create an academic exchange atmosphere conducive to stimulating innovative thinking for postgraduate students.}

As for the cold area research center of Jilin Jianzhu university, we attach great importance to the construction of soft environment while actively striving to build hard environment. In the daily life and work of the center, we strive to create an academic exchange atmosphere conducive to stimulating students' innovative thinking in order to broaden the horizons of postgraduate students and help them find suitable research projects. The concrete measures are as follows:

\subsection{Regular academic lectures will be held}

With the constant attempts of postgraduate teaching beneficial to reform, the well-known experts and scholars from home and abroad will be invited irregularly to lecture in the center in order to constantly expand the postgraduate student academic vision and improve the quality of the cultivation of postgraduate students as well as improve the comprehensive quality of young teachers and supervisors. On this basis, the director of the center as the representative of the scholars and professors also regularly holds series of academic reports, lectures and academic forums.

\subsection{Postgraduate students are encouraged to participate in various civil engineering academic conferences at home and abroad}

In order to strengthen the postgraduate students' understanding toward the latest information about research fields related to civil engineering and broaden academic exchange space among colleges and universities, the student will be encouraged by the center to participate in a variety of domestic and international academic conferences related to civil engineering. With efforts to write the conference papers and take an active part in the conference communication and speech and through mutual learning and exchanges, the students' interest in learning is greatly promoted, and the students' learning ability and capability of oral communication in public and reporting abilities are improved and enhanced. The main expenses for the postgraduate students to attend the conference are generally paid from the supervisor's research funds, and the engineering research center also has corresponding incentive policies to support the students to attend the conference.

\subsection{Regularly organize postgraduate students academic salon}

Postgraduate students from the engineering research center hold regular academic salons every Friday afternoon. The host of the academic salon is held by the director of the center or the secretary in turn. According to the actual progress of the project, the host can also be held by the supervisor. The academic salon topic is indefinite and informal, and there are postgraduate students from relevant research groups to introduce the good literature they have read so far. There are young teachers or supervisors to introduce their own learning or scientific research work experience and lessons. According to the specific situation of the project, reporting the progress of the project. After discussion, the controversial academic views are recognized anew, and innovative ideas emerge in an endless stream. All the participated postgraduate students have been edified and enlightened in such a strong atmosphere of academic exchanges and gradually enhanced their scientific research ability.

\section{Establish and perfect the corresponding management team}

In the daily actual contact with postgraduate students, we found the master postgraduate student of grade one commonly had dependency, lacking of initiative in learning, some students just complete the specific tasks assigned by the supervisor. And because that there is no instructor management system during the postgraduate phase like the ones during the undergraduate phase, students more or less will slacken their efforts in learning. Those students with poor independent learning ability are difficult to make achievements in related fields, or even fail to meet graduation requirements. In the end, it is those students with strong independent learning ability will achieve scientific research outcomes. In practical work, the engineering research center attaches great importance to the role of the center's management personnel, because effective management is the indispensable and most 
dynamic part of the organizational system. During the daily management work in the center, where the center secretary will get into the bottom of the students' study and life, becoming their close friends and urging them to complete the training of postgraduate students during the process, which will in general boost their progress and well-being in various aspects.

\section{Conclusion}

After several years of practical work, we accumulated a lot of practice experience of postgraduate students training. Along with the strengthening of the students' basic theory studying through the specific way of postgraduates cultivating in the center, the students' scientific research capability was improved and their scale of knowledge was expanded, making the benign interaction between the postgraduates and the supervisors come true, which greatly improved the quality of the postgraduate students training in the engineering research center, and further promoted the overall level of scientific research in the center.

\section{Acknowledgment}

This research was financially supported by National education science planning key Project (DIA150316.

\section{References}

[1] Wei jinping. Postgraduate training mode of local universities - the exploration of industry-university-research cooperative education [J]. Journal of national school of education administration,2008, (09):65-68

[2] Hu linglin. Research on postgraduate training mode in Chinese universities [D]. East China normal university.2004.

[3] Yang dixin. Innovative postgraduate training mode with the advantage of engineering technology center [J]. Shaanxi education (higher education edition),2009,(09): 111-+118 